\title{
A Química na Literatura
}

\author{
Maria Helena Santana \\ Universidade de Coimbra - Centro de Literatura Portuguesa \\ mahesa@fl.uc.pt
}

\begin{abstract}
O
diálogo da cultura literária com as diversas ciências atravessa a História do Ocidente correlacionando-se com o tema do Progresso. Na época que se seguiu ao Iluminismo, essa relação torna-se fracturante, na medida em que o desenvolvimento da ciência experimental - nomeadamente a Química - rivaliza com o poder simbólico da cultura humanística. Através de dois romances portugueses da viragem do século XIX para o século XX, propõe-se uma breve reflexão acerca do nascimento da era tecnológica: embora celebrado como uma grande conquista da modernidade, o progresso tecno-industrial é sobretudo sentido como uma ameaça, quer aos valores tradicionais quer à “civilização” e à "natureza”.
\end{abstract}

No século XIX, sempre que os romancistas precisavam de representar um homem de ciência, uma das áreas preferidas costumava ser a Química. Os motivos parecem compreensíveis: não só a disciplina estava então num grande momento de expansão, mas sobretudo porque o estereótipo mais comum do cientista era o do homem de bata branca, isolado do mundo no seu laboratório, vergado sobre tubos de ensaio e substâncias misteriosas ao comum dos mortais. Sucedia também tornarem-se obcecados e perderem o contacto com a vida real. Assim acontece em La Recherche de l'Absolu, de Balzac (1834) onde o “sábio”, ainda uma espécie de alquimista, fica praticamente louco, na ânsia de produzir diamantes a partir da cristalização do carbono.

Reencontramos a mesma temática num romance português já mais tardio, do escritor Teixeira de Queirós [1], A Grande Quimera (1919), cujo protagonista é também um químico. O cientista do nosso romance, Manuel de Sá, é jovem e moderno: estudou no estrangeiro, já usa um microscópio, lê as revistas internacionais da especialidade. Trabalha com o objectivo nobre de penetrar nos segredos da Natureza, e não com um sentido utilitário; por sorte dele, não precisa de trabalhar nem de publicar para subsistir: investiga por conta própria e por gosto, num laboratório privado, montado em sua casa (nesta época ainda era possível fazer ciência amadorística, fora do meio universitário ou empresarial).

Manuel tinha uma visão negativista da sociedade: via o mundo de longe, à luz das leis da Natureza, e descria da bondade humana. Mas acreditava no poder salvífico da ciência como a única forma de remissão da "barbárie original”; através dela poderia haver esperança de aumentar o bem-estar comum e de superar as iniquidades sociais:

"As ciências naturais traziam à terra maldita, o imaginado paraíso. O braço do obreiro já descansava à sombra das aplicações do calor e da electricidade. Só faltava que a química fabricasse o sustento diário dum homem, representado numa pastilha alimentar, como o desejou Berthelot, para haver felicidade completa sobre a terra. Depois disto, os grandes problemas do proletariado inquieto teriam a solução natural, e a equiparação dos homens pelo nivelamento satisfatório das necessidades urgentes da vida, estaria realizada. Os químicos e os outros sábios substituiriam o Deus antigo e omnipotente, facultando à colectividade social, com mui pequeno esforço, tudo quanto ela precisava para ser ditosa.” (p. 63).

Absorvida pela ciência-redentora, a crença religiosa deixaria, portanto, de ter sentido. É este um dos sofismas que o livro pretende desmontar. A certa altura, o cientista trava-se de razões com um velho padre, que lhe faz um sermão contra o progresso material:

\footnotetext{
“Corrigir a obra de Deus! Vanitas vanitatum, et omnia vanitas! Máquinas para voar e outras para a navegação por baixo de água! Deus criou o ar para as aves e o mar para os peixes, morgado, di-lo claramente o Genesis. (...) Já mais que uma vez lho tenho dito, isso a que chamam progresso tem acarretado mais males do que bens. A felicidade humana consiste na boa prática dos mandamentos do Sinai, como os ensina a nossa religião. O progresso material seca as almas, tira-nos a consolação de sermos humildes.” (p. 182-7)
}

A história prossegue: Manuel de Sá está à beira de começar uma aventura prometeica: trata-se da descoberta de um novo tipo de dinamite (a "mongite”), que viria coroar de êxito a sua carreira. O sacerdote, como seria de esperar, reage mal ao grande invento: "Mas, senhor morgado (...) não seria preferível inventar coisa que edifique, em vez de se propor a destruir o que está criado?” Manuel ouve-o com respeito, mas mantém-se confiante no advento de uma nova era cerebral: "Destruímos, caro amigo, para edificar mais perfeito. Toda a ciência é construtiva”. Considera, além disso, que a ciência equipara os homens, é democrática e "não pede certidão de baptismo ao talento".

O cientista tinha, porém, ideias confusas em matéria de “moral política”, e criara simpatia pelo movimento anarquista; recebe então a visita de dois operários militantes que lhe pedem colaboração para uma acção revolucionária. Confrontado com a utilização política, destruidora, do explosivo, a sua consciência moral começa a despertar: 
“Não é para aniquilar o trabalho do homem, e o próprio homem, que a ciência conquistou à terra forças que nela existem mortas. Os explosivos devem ter um emprego harmónico com a justiça social, ajudando o nosso braço e não destruindo-o. Há tanta obra de paz a empreender, e aí é que os devemos aproveitar, com o fim de substituir a picareta, o martelo e toda a pena corpórea” (p. 89-90).

A arrogância científica recebe o golpe final com a explosão do laboratório. O desastre, provocado por incúria de um ajudante, deixa um rasto de mutilação e morte. E a lição filosófica a retirar da catástrofe é de alienação e de culpa. Manuel descobre então que a felicidade não se encontra na fama, mas nas coisas simples da vida: o estudo honesto, o amor da família, a paz campestre. Fica assim patente, com esta alegoria, o medo que a sociedade, bastante conservadora, começa a ter do poder da ciência aplicada, da sua capacidade infinita de transformar o mundo e os modos de vida ancestrais.

São muitos os escritores do século XIX a pensarem deste modo. Em geral escrevem romances muito pessimistas, em que se questiona o valor e a utilidade da ciência, a cultura materialista e o espaço possível da felicidade [2]. Inspiravam-se no pensamento de Ruskin, Schopenhauer e Tolstoi - alguns dos autores que mais contribuiram para exprimir o desencanto civilizacional do fim-de-século. Todos eles condenam a cultura iluminista, considerando que o racionalismo instaurado a partir do século XVIII interrompeu toda uma orientação cultural fundada no "espírito”. Em última instância, seria o “demónio de Sócrates” do Ocidente (i.e., a orientação científica), o responsável pelo desvio histórico, anti-espiritual, da nossa civilização.

Compreende-se que o balanço crítico, vindo de homens de letras, seja predominantemente negativo. O triunfo da civilização tecnológica associa-se à crise do paradigma cultural de matriz filosófica e humanística que caracterizou a tradição ocidental no seu conjunto. A submersão da cultura pela técnica começa então a ser pressentida com algum dramatismo, sentimento que se acentuará no século XX. Na rejeição do materialismo - sinónimo desqualificador do progresso - é já bem visível o receio de uma modernidade entregue à sua dinâmica de entropia, onde os valores espirituais pouco ou nada significam. Como bem sintetiza Gianni Vattimo,

\footnotetext{
"A técnica aparece como a causa de um processo geral de desumanização que compreende quer o obscurecimento dos ideais humanistas da cultura, a favor de uma formação do homem centrada na ciência e na habilidade produtiva racionalmente dirigida, quer, no plano da organização social e política, um processo de acentuada racionalização que deixa entrever os traços da sociedade da organização total descrita e criticada por Adorno”. [3]
}

Esta é aliás uma antinomia recorrente. Desde o Iluminismo, o conceito de progresso foi objecto de sucessivas projecções de euforia e demonização. Observa Robert Nisbet, num estudo clássico sobre o tema [4], que duas tendências se cruzam dialecticamente na história do pensamento ocidental: de um lado a convicção (dominante) que correlaciona o progresso com um aperfeiçoamento cumulativo do saber; do outro a ideia de que a evolução, a existir, assenta em critérios não-objectivos, como seja o aperfeiçoamento moral ou espiritual da natureza humana. Para esta linha de pensamento, o conhecimento e a própria civilização tendem a ser encarados negativamente.

O fosso começa a acentuar-se no Iluminismo e torna-se evidente no século XIX: em 1829, já Thomas Carlyle caracterizava o seu tempo como a "era mecânica”, que viera substituir a "era filosófica e moral”; e lembrava que a nossa felicidade depende sobretudo da nossa mente, e não das circunstâncias que estão fora de nós [5]. A ciência oitocentista encarregar-se-ia em breve de o desmentir: como sabemos, o darwinismo desacreditou a teologia criacionista e pôs em causa a imagem do Universo centrada no Homem.

Já o positivismo, herdeiro das Luzes, empenhou-se em valorizar o progresso científico, enquadrando-o numa visão optimista do mundo, de base racional: a fé no desenvolvimento científico, em que assenta a ‘filosofia’ positiva, supunha uma evolução paralela da organização social, orientada para o bem-estar dos cidadãos. O homem perdia um certo sentido de harmonia com o mundo, mas em contrapartida tornava-se agente do seu destino colectivo, sujeito da História.

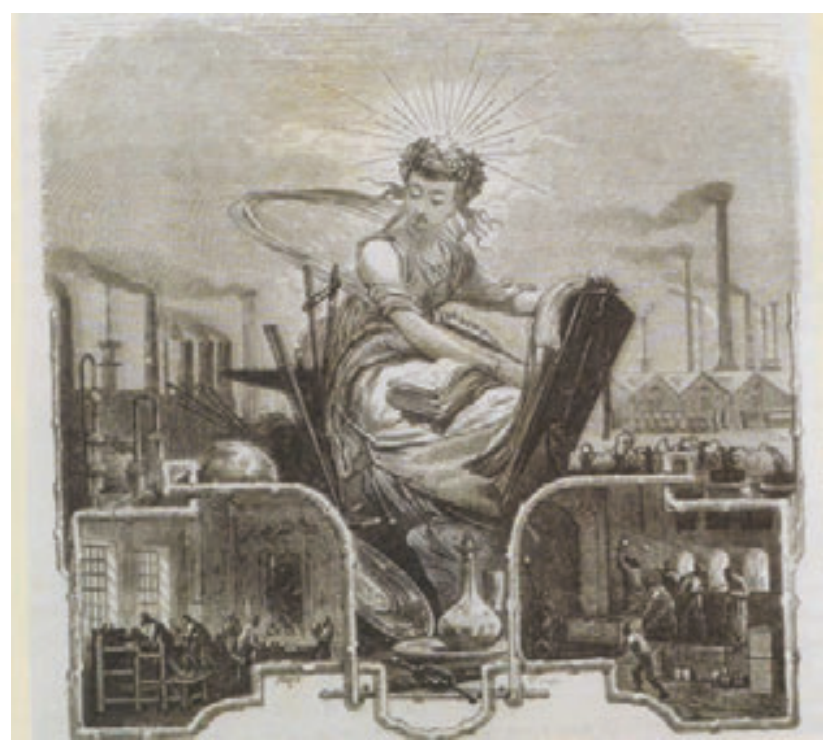

Ilustração do livro de Louis Figuier Les Merveilles de l'Industrie (4 vols., 1873-1877)

Todavia, na era da Revolução Industrial, a ideia de progresso científico não se define apenas por belas abstracções especulativas. A tecnologia constitui doravante a sua manifestação mais evidente: por maior que seja a importância cognoscitiva do método experimental, das leis da hereditariedade ou do transformismo, dificilmente os conceitos teóricos podem competir com a realidade visível da máquina, da luz eléctrica, da telegrafia sem fios - para apenas mencionar alguns dos inventos mais emblemáticos do século [6]. A imprensa, rendida, divulga as maravilhas da mecanização, e as exposições industriais, em toda a Europa, celebram o seu triunfo. Nascia uma confiança, muitas 
vezes desmesurada, nos instrumentos de aperfeiçoamento e domínio da Natureza; esperava-se a libertação do trabalho e o incremento da riqueza e do conforto.

Por outro lado, crescia o receio de que a indústria, cada vez mais dirigida para os interesses mercantilistas, desviasse a ciência do seu destino primordial. Nas últimas décadas do século, com o desenvolvimento do capitalismo industrial, esta perspectiva tinha forçosamente que considerar-se. A técnica, entregue à sua própria dinâmica, ameaçava escapar ao controlo de qualquer poder exterior. A função reguladora, que as então recentes ciências sociais chamaram a si, cedo começou a revelar-se inoperante. Vemos então os ideólogos, passada a euforia positivista, alertar para as dimensões incontroláveis do desenvolvimento, quer no plano social (os problemas decorrentes da proletarização), quer no plano ético, como seja a distribuição da riqueza e o uso indiscriminado dos recursos naturais. Assim o seu discurso assume não raro uma tonalidade catastrofista: em lugar da realização da felicidade colectiva, o progresso geraria a anarquia e a perda da identidade humana e cultural.

Nas literaturas europeias surgem, a partir do século XIX, imagens futuristas de um mundo ultra-mecanizado, mas sob a ameaça do caos ou da desumanização [7]. Nada que nos surpreenda: ainda hoje a ficção científica denuncia essencialmente a fascinação e o medo dos demónios que a Ciência liberta. Em Portugal este tipo de literatura não tem grande tradição, mas Eça deixou-nos um humorístico exemplo no seu último romance, A Cidade e as Serras, onde descreve o absurdo existencial de um homem moderno, rodeado pelas últimas maravilhas da tecnologia do seu tempo; como sabemos, acabará por se refugiar, enfastiado, na sua velha quinta duriense, livre das amarras da “civilização”.

Cabe a este propósito mencionar um outro romance de Teixeira de Queirós - O Famoso Galrão, de 1898 [8] -, em que um self made man, imigrante português nas Américas, decide criar uma grande companhia de fomento (uma empresa de base tecnológica, como hoje se diria). Para isso recorre aos conhecimentos de um sábio alemão, de grande inteligência mas algo exótico (na representação ficcional, os sábios do século XIX tendem a ser alemães, e normalmente são alvo de troça). Trata-se, mais uma vez, de um especialista em química (industrial), que fica encarregado de produzir extraordinárias patentes: entre os novos inventos destacam-se uma linha de produção de cortiça e outra de ovos artificiais, e um "elixir de temperatura normal”, a distribuir em pastilhas, que funcionaria como um condicionador corporal. Todos estes inventos pareceriam risíveis, embora decerto alimentassem as fantasias científicas da época.

Mais tarde os dois amigos voltam a encontrar-se na América: o sábio ocupava-se agora de um novo processo de síntese do açúcar e de um acumulador eléctrico para aproveitamento da força das marés. E acabam por fundar uma fábrica de manteigas transformadas, extraídas de gordura mineral.

A ideia de substituir a Natureza por produtos sintéticos causa estranheza, mas é a ânsia de riqueza que destrói o sonho: a grande Companhia de Fomento não vinga, porque o dinheiro dos accionistas é desencaminhado; e a fábrica americana vai à falência porque uma paixão infeliz desconcentra o aventureiro dos negócios. O romance pretende criticar os perigos do dinheiro no sistema capitalista nascente, mas a moral da história bem podia ser outra, de natureza psicológica: o "empreendedorismo" dá-se mal com o temperamento português.

Ganha assim expressão, no discurso ideológico e literário do fim-de-século, uma corrente antiprogressista que muitas vezes se classifica de reaccionária; com alguma razão, na medida em que entra em ruptura com a realidade do seu tempo. Como sabemos, trata-se em parte de um fenómeno cíclico, embora dramatizado em circunstâncias histórico-culturais concretas. Já antes acontecera com reacção romântica às Luzes, e voltará a verificar-se repetidamente, até aos movimentos ecologistas e "new age" dos nossos dias. À sociedade mecânica e utilitária opõe-se então a reconversão aos valores do espírito, tendo por vezes como corolário o retorno a um estado civilizacional anterior, pré-moderno e pré-científico. O ideal da paz campestre apresenta-se frequentemente como alternativa - uma alternativa igualmente mitificante e utópica, já se vê. O relógio do progresso nunca anda para trás.

O presente texto foi apresentado por ocasião da jubilação do Prof. Sebastião Formosinho, em 20 de Setembro de 2013. Agradeço o convite ao Sr. Director do Departamento de Química da Universidade de Coimbra.

\section{REFERÊNCIAS}

[1] Francisco Teixeira de Queirós (pseudónimo Bento Moreno) é autor de um ciclo de romances, "Comédia Burguesa”, alguns dos quais de tema científico: O Famoso Galrão (1898), A Caridade em Lisboa (1901) e A Grande Quimera (Lisboa, Parceria A. M. Pereira, 1919).

[2] Para uma visão mais abrangente do tema cf. M. H. Santana, Literatura e Ciência na Ficção do Século XIX. Lisboa, INCM, 2007, cap. VI.

[3] G. Vattimo, “A crise do humanismo", in O Fim da Modernidade (trad.), Lisboa, Presença, 1987, p. 32.

[4] R. Nisbet, History of the Idea of Progress, London, Basic Books, 1980, cap. I.

[5] T. Carlyle, Signs of the Times, in Selected Writings, Penguin Books, 1971, pp. 64 e 71.

[6] Cf. A. M. Baptista, A Primeira Idade da Ciência. A Ciência no Século XIX e Tempo de D. Carlos I (1863-1908), Lisboa, Gradiva, 1996.

[7] Cf. E. G. Ingersoll, Representations of Science and Technology in British Literature since 1880, London, Peter Lang, 1994; J. Noirai, Le Romancier et la Machine. L'Image de la Machine dans le Roman Français (1850-1900), Paris, José Corti, 1981.

[8] F. T. Queirós, O Famoso Galrão, Lisboa, Livr. Editora Tavares, Cardoso \& Irmão, 1898. 


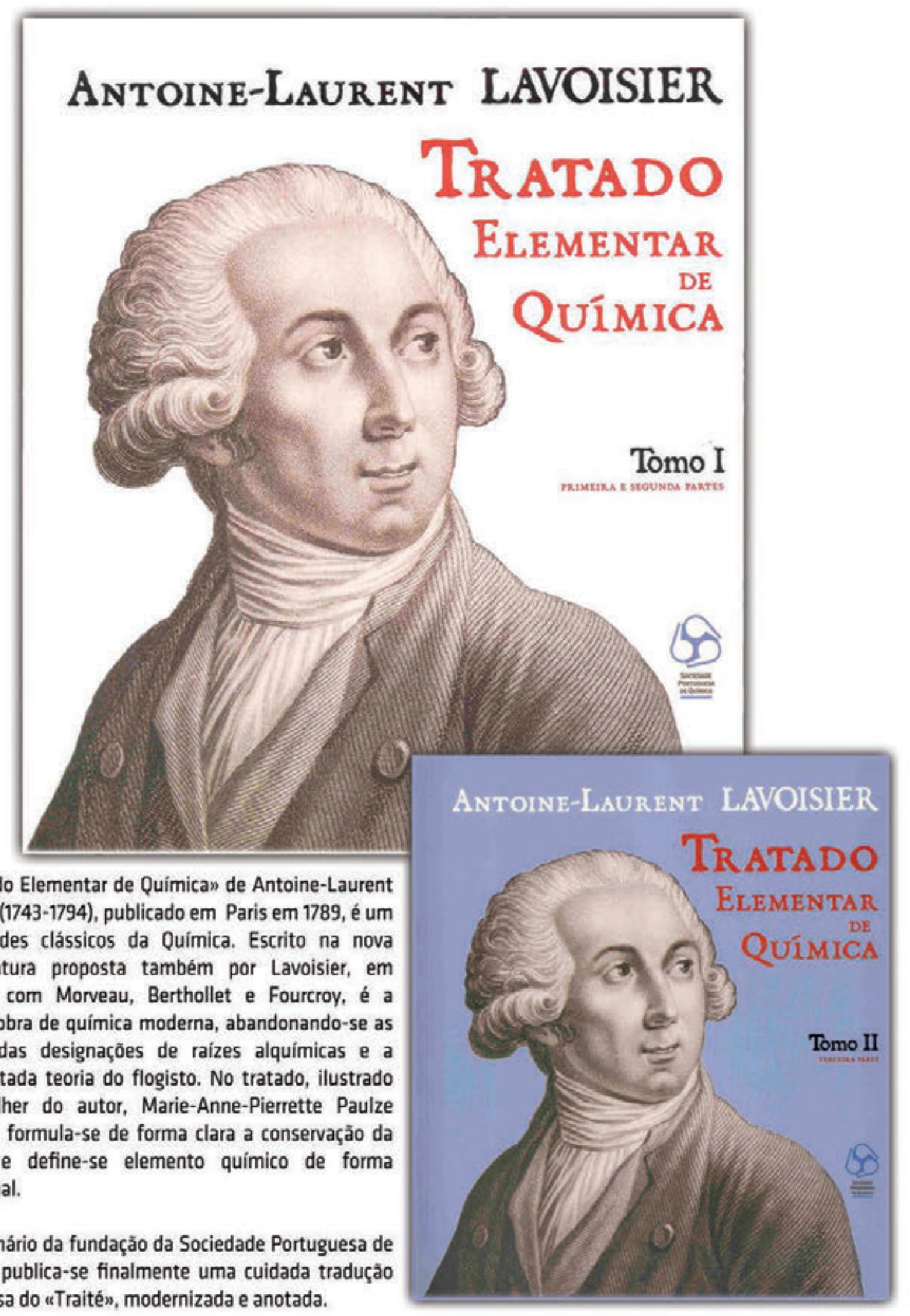

0 «Tratado Elementar de Químican de Antoine-Laurent Lavoisier (1743-1794), publicado em Paris em 1789, é um dos grandes clássicos da Química. Escrito na nova nomenclatura proposta também por Lavoisier, em conjunto com Morveau, Berthollet e Fourcroy, é a primeira obra de química moderna, abandonando-se as inadequadas designações de raízes alquímicas e a desacreditada teoria do flogisto. No tratado, ilustrado pela mulher do autor, Marie-Anne-Pierrette Paulze Lavoisier, formula-se de forma clara a conservação da matéria e define-se elemento químico de forma operacional.

No centenário da fundação da Sociedade Portuguesa de Química, publica-se finalmente uma cuidada traduçâo portuguesa do "Traitén, modernizada e anotada. 